\title{
Analysis of Potential Concrete Floor Decontamination Technologies
}

\author{
Final Report \\ August 6, 1997
}

\author{
By: \\ M. A. Ebadian
}

Work Performed Under Contract No.: DE-FG21-95EW55094

For

U.S. Department of Energy

Office of Fossil Energy

Federal Energy Technology Center

P.O. Box 880

Morgantown, West Virginia 26507-0880

By

Florida International University

Hemispheric Center for Environmental Technology (HCET)

Center for Engineering \& Applied Sciences

10555 West Flagler Street

EAS-2100

Miami, Florida 33174 


\section{Disclaimer}

This report was prepared as an account of work sponsored by an agency of the United States Government. Neither the United States Government nor any agency thereof, nor any of their employees, makes any warranty, express or implied, or assumes any legal liability or responsibility for the accuracy, completeness, or usefulness of any information, apparatus, product, or process disclosed, or represents that its use would not infringe privately owed rights. Reference herein to any specific commercial product, process, or service by trade name, trademark, manufacturer, or otherwise does not necessarily constitute or imply its endorsement, recommendation, or favoring by the United States Government or any agency thereof. The views and opinions of authors expressed herein do not necessarily state or reflect those of the United States Government or any agency thereof. 


\section{DISCLAIMER}

Portions of this document may be illegible in electronic image products. Images are produced from the best available original document. 
ABSTRACT ...ii

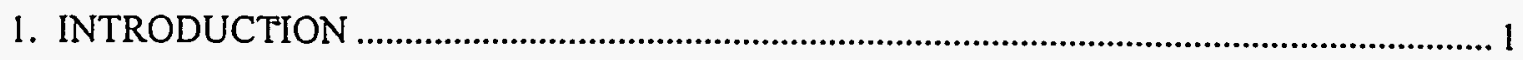

1.1 BACKGROUND OF THE FERNALD ENVIRONMENTAL MANAGEMENT PROJECT.

1.2 PURPOSE OF INVESTIGATION. 1

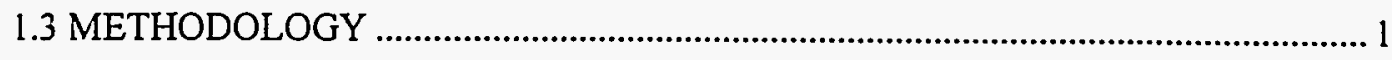
1

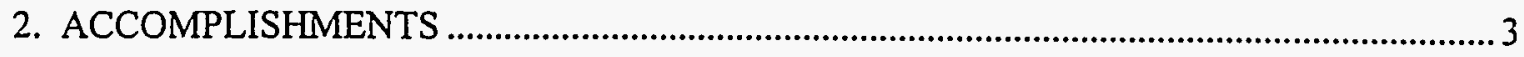

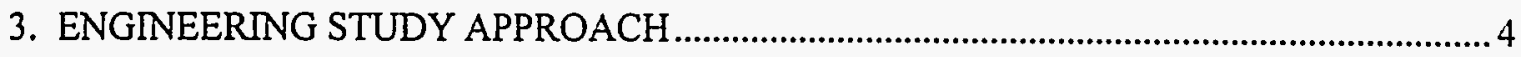

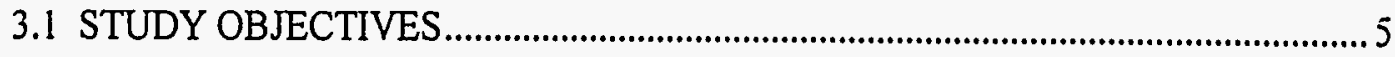

3.2 DETERMINING THE TYPES OF TECHNOLOGIES TO BE TESTED ...................5

3.3 DESCRIPTION OF THE TECHNOLOGIES TESTED.............................................

37 1. Ultra High:Pressure Water......................................................................

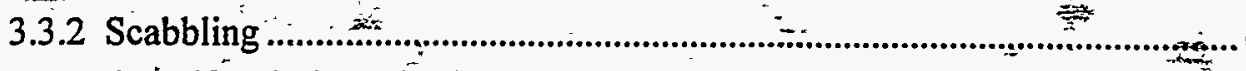

3.3.3 Centrifugal Shot Blasting ………………...............................................

3.4 EMERGING CONCRETE REMOVAL TECHNOLOGIES …................................. 8

3.5 SURROGATE SELECTION AND PREPARATION.................................................. 8

3.6 COMPARISON OF THE END POINTS ACHIEVED TO THE

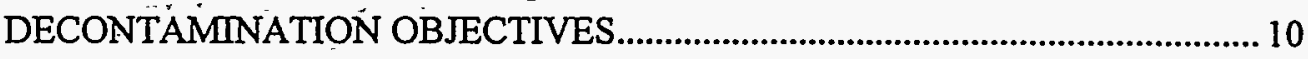

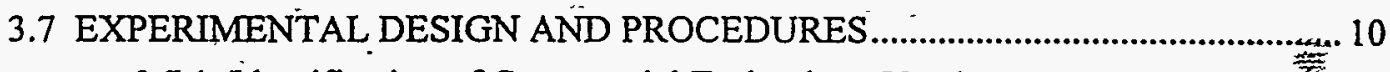

3.7.1 Identification of Commercial Technology Vendors................................. 11

3.7.2 Test Location and Utility Parameters ........................................................... 11

3.7.3 Test Equipment, Personnel, and Materials ................................................. 11

3.8 DATA REQUIREMENTS AND SAMPLE COLLECTION METHOD ................... 12

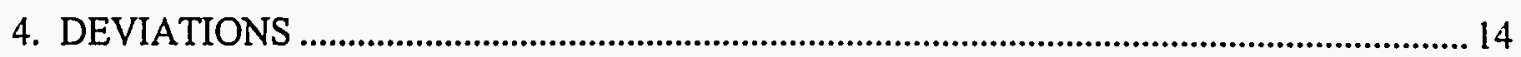

5. TECHNOLOGY RECOMMENDATIONS.............................................................15

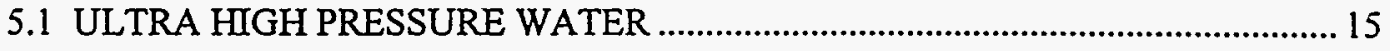

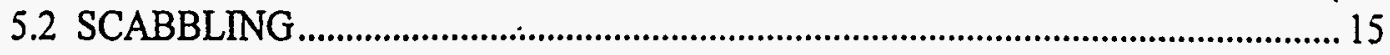

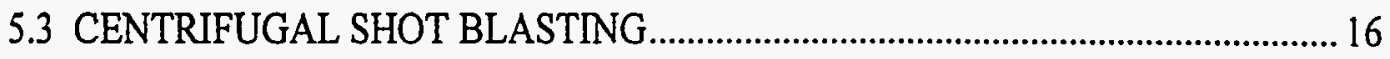

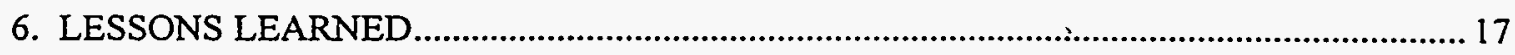

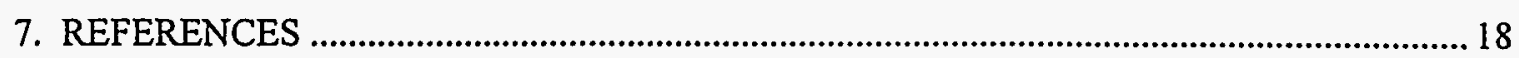

APPENDIX A: Technology Data Requirements: Definitions

APPENDIX B: Data Requirements for Ultra High Pressure Water, Centrifugal Shot Blast, and Scabbling

APPENDIX C: Data Requirements for Milling and Steel Grit Vacuum Blasting

APPENDIX D: Vendor Data 


\section{INTRODUCTION}

\subsection{BACKGROUND OF THE FERNALD ENVIRONMENTAL MANAGEMENT PROJECT}

During the decontamination and decommissioning (D\&D) activities to be conducted at the Fernald Environmental Management Project (FEMP), contaminated concrete waste will be generated from the D\&D of approximately 200 buildings and other structures [1].

The U.S. Department of Energy (DOE) owns the Fernald site. The site is a contractor-operated federal facility that produced high-purity uranium metal products for the DOE and its predecessor agency, the Atomic Energy Commission, from 1952 to 1989. Thorium bearing ores were also processed at FEMP, but on a smaller scale. Production activities ceased in 1989, and the production mission of the facility ended formally in 1991.

FEMP was included on the Comprehensive Environmental Response, Compensation, and Liability Act (CERCLA) National Priorities List in 1989. The current mission of the site is environmental restoration according to the requirements specified by CERCLA [1]. Decontamination and decommissioning activities require the treatment of concrete floors to segregate technetium-99 contaminated concrete from the remainder of the concrete. Many proven commercial surface removal technologies are available. These processes vary in aggressiveness, safety requirements, waste generation, capital requirements, and operating and maintenance costs.

\subsection{PURPOSE OF THE INVESTIGATION}

The FEMP contracted the Hemispheric Center for Environmental Technology (HCET) at Florida International University (FIU) to identify the applicability, cost, performance capabilities, and limitations of commercially available techniques for the aggressive removal of one inch of concrete surface layer. As required by the Operable Unit 3 Record of Decision, one inch of concrete must be removed from 20,000 square feet of concrete floor. This study focused on achieving these specific objectives and is not intended to be a general assessment of the complete spectrum of concrete surface removal technologies.

\subsection{METHODOLOGY}

The assessment and selection of the appropriate and most effective technology to meet the remediation objectives for concrete floors is a difficult process. A single information source comparing technologies in the areas of safety, cost, and effectiveness is not currently available. The information found in DOE/ORO/2034 Contaminated Concrete: Occurrence and. Emerging Technologies for DOE Decontamination [3] was used as the foundation for this study. This report provided background information on the DOE's complex-wide problem and aided in selecting technologies for field testing. 
To enhance the technology assessment process. the International Union of Operating Engineers (IUOE) provided a review of health and safety factors pertinent to the technology tests. This review was performed as an integral part of the field demonstrations held on the campus of Florida International University. 


\section{ACCOMPLISHMENTS}

This study provides a source of comparable data for concrete floor nuclear surface removal using commercially available technologies. A summary of the data related to production rates is provided in Figure 1 (see below). The information provided in this figure may be misleading if not used in concert with Appendixes B and C. Together, the figure and tables provide an overall picture of the capability of each technology tested. The information presented may be used to determine the most appropriate technology that meets site-specific health and safety, operations, and waste management factors. The data presented in Appendixes B and C comprise the deliverables of this study.

Conclusions and recommendations are discussed in detail in later sections. A summary of these findings and conclusions follows:

- The technologies demonstrated operational characteristics that should be considered before implementing a technology. The site field engineer should be aware of the benefits and limitations posed by each technology and apply those which best suit the conditions. The data presented in Appendixes B and $\mathrm{C}$ represent the factors that are required to make these sitespecific conclusions;

- Currently, it is not possible to accurately quantify the amount of surface material removed by a particular technology. The vendor performed a rough estimate of the concrete removed using a tape measure and $\mathrm{a} 2$ in. $\times 4$ in. piece of lumber as a straight edge. The method employed by FIU to verify results also had some variability $( \pm 0.03 \mathrm{ft}$.); and

- An accurate, reliable, and simple method of determining the amount of surface removed by a particular technology should be developed in order to completely assesses the overall effectiveness of each technology.

Within each technology class, a group of subcategories has been reviewed. These individual subcategories offer technology alternatives that may improve the technology's overall viability with respect to achieving individual remediation objectives. These technological differences, which are beyond the scope of this study, may be the subject of future investigation.

Figure 1 presents a summary of the results of the technologies tested. As stated above, this figure is not intended for use alone, but in concert with Appendixes B and C. Figure 1 summarizes the production rate for each technology in square feet per hour of surface removed. Depth of removal is denoted by the shading of the bar representing each technology. However, the most appropriate technology for a particular project and site must be determined by the integration of many factors and considering the factor that is the most important for a particular site, e.g., production rate, cost, health and safety, secondary waste generation, or efficiency.

Figure 1 also presents production rate data for two technologies that were not required to remove one inch of concrete. These technologies are milling and steel grit vacuum blasting. These tests were performed during the same period of time as the technologies required to remove one inch of concrete and are presented as valuable information for site personnel requiring a lesser degree of surface removal. 


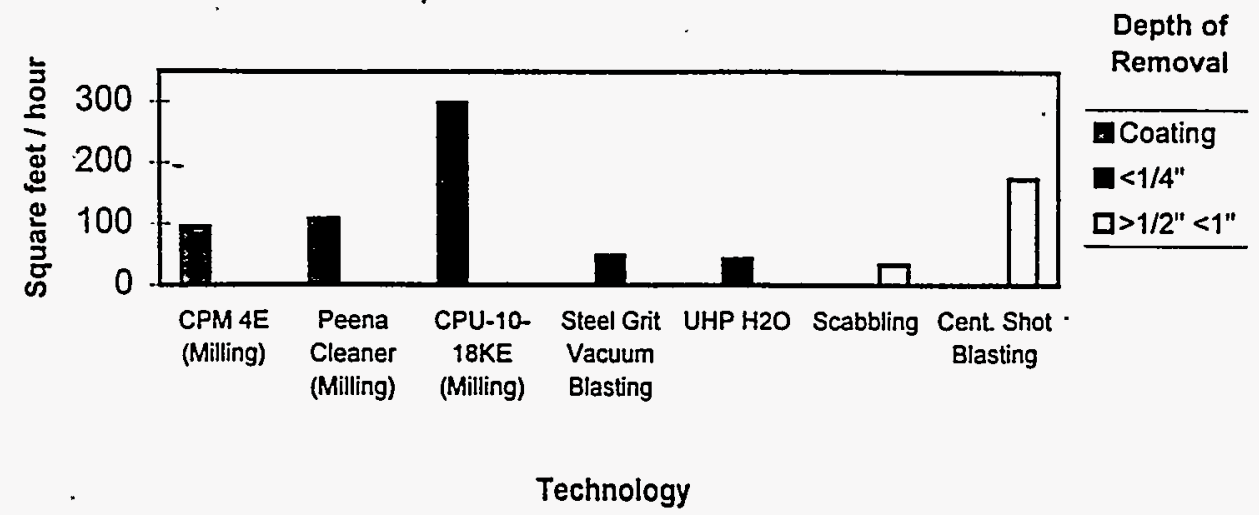

Figure 1. Production rates. 


\section{ENGINEERING STUDY APPROACH}

\subsection{STUDY OBJECTIVES}

The objectives of this study were to perform a comparative analysis of commercially available concrete floor surface removal technologies applicable to the decontamination and decommissioning (D\&D) of FEMP structures and assess their applicability to other environmental restoration sites. The basis for this comparative analysis included:

- Determining the types of technologies to be tested;

- Surrogate selection and preparation; and

- Comparing the end point achieved to FEMP's remediation objectives.

\subsection{DETERMINING THE TYPES OF TECHNOLOGIES TO BE TESTED}

Established sources and databases were used to categorize the technologies and perform the initial screening of technology types. These sources and databases included:

- DOE/EM-0142P Decommissioning Handbook [5];

- ORNL/M-2751 Oak Ridge National Laboratory Technology Logic Diagram [6];

- EGG-WTD-11104 Idaho National Engineering Laboratory Decontamination and Decommissioning Technology Logic Diagram [7];

- DOE/ORO/2034 Contaminated Concrete: Occurrence and Emerging Technologies for DOE Decontamination [3];

- Remedial Action Program Information Center (RAPIC) database; and

- Fernald Environmental Restoration Management Corporation (FERMCO), 1993, Operable Unit 3 Remedial Investigation and Feasibility Study Work Plan Addendum, Final, U.S. Department of Energy [2].

These sources provided a screening based on the applicability of a technology to a given material and contaminant. Considering this review, the following commercially available technologies were tested:

- Ultra high pressure water $(<55,000 \mathrm{psi}$ and $>15,000 \mathrm{psi})$;

- Scabbling; and

- Centrifugal shot blasting.

Two additional technologies that are not directly applicable to the FEMP's remediation objectives were evaluated as part of this study. These are included in this report for the benefit of other remediation sites with different objectives. These technologies were:

- Milling; and

- Steel grit vacuum blasting; 


\subsection{DESCRIPTION OF THE TECHNOLOGIES TESTED}

Sections 3.3.1 through 3.3.3 provide descriptions and photographs of the technologies tested for their ability to meet the FEMP's remediation objectives. The description and photographs of the two additional technologies are presented in Appendix D.

\subsubsection{Ultra High Pressure Water}

The ultra high pressure technology employs a triplex pump driven by a six-cylinder diesel engine. The pump generates up to 40,000 pounds per square inch (psi) of water pressure. This ultra high pressure pump supplies water to a system of rotating nozzles that sprays the water stream onto the surface of the concrete. The coating and substrate are removed by the kinetic impact of the water stream. The contamination and the coating are flushed away from the surface. Water systems have the capacity to reach and flush convoluted surfaces. A standard water supply with a capability of six gallons per minute is required.

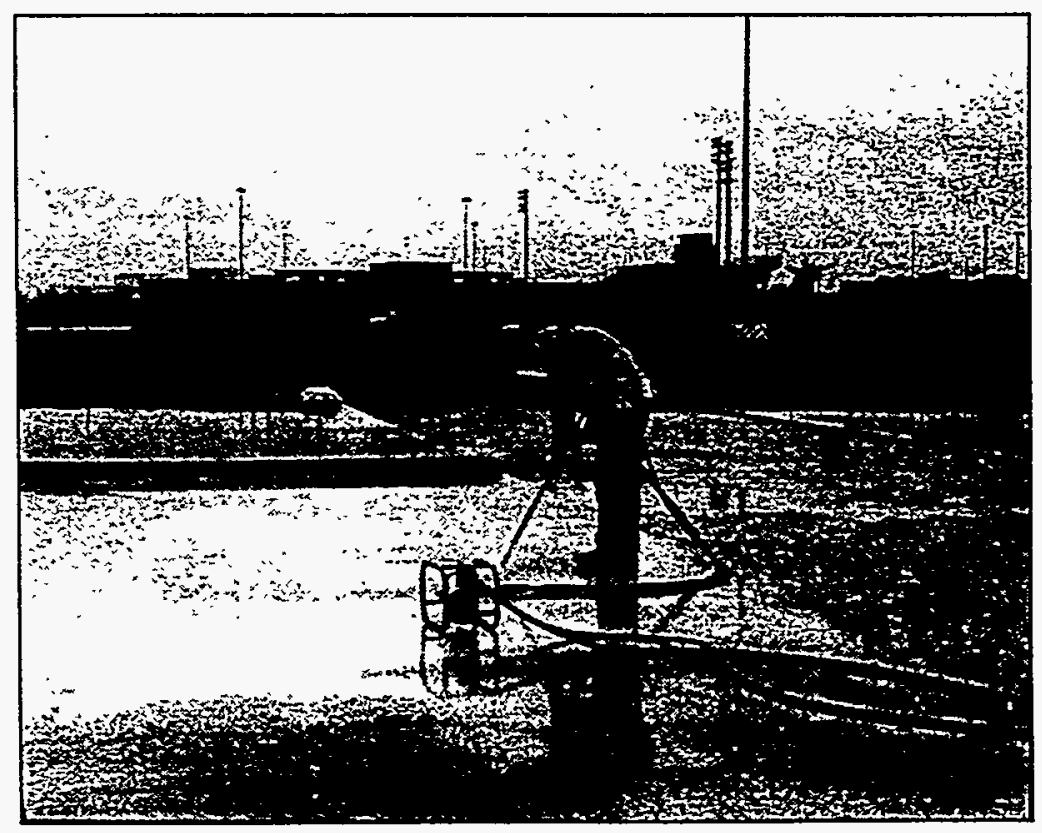

Figure 2. Ultra high pressure water.

\subsubsection{Scabbling}

The technology assessment of scabbling combined the $\mathrm{MOOSE}^{\circ}$, the Squirrel $\mathrm{I}^{\circ}$, the Squirrel III $^{\circ}$, and the Corner-Cutter ${ }^{\circ}$. Scabbling systems use mechanical force generated by compressed air to impact the surface and remove material. Tungsten bits are driven in a piston action to impact the surface. Vacuum and dust collection are integrated into the scabbling system to collect the debris removed. The system utilizes compressed air to drive the vacuum system and the dust collector. The bits eventually become dull and must be periodically replaced due to repeated impact with the concrete surface. The integrated scabbling system demonstrated by 
Pentek was specifically designed for nuclear service. The MOOSE ${ }^{\circ}$, in combination with the other auxiliary tools, provides the capability to apply the scabbling process to every surface of the floor, including edges, corners, and other tight geometries that can be expected to exist at the FEMP.

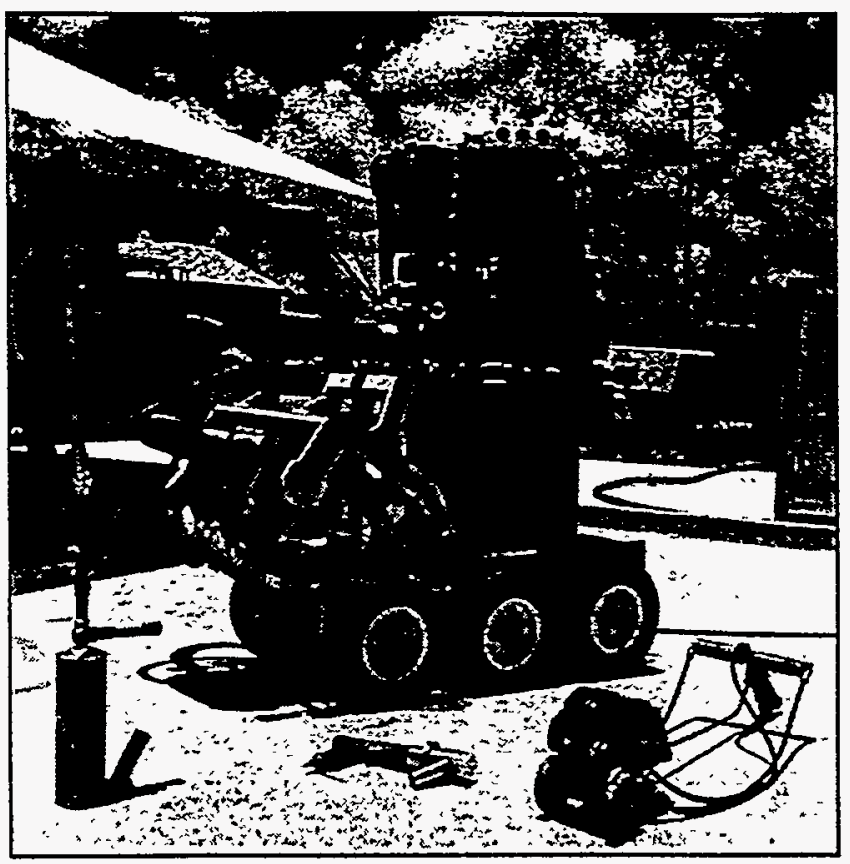

Figure 3. Scabbling system.

\subsubsection{Centrifugal Shot Blasting}

The centrifugal shot blasting technology consists primarily of a blast head and a vacuum system. Hardened steel shot is propelled at a high rate of speed from the blast head to abrade the concrete surface. The concrete debris and the steel shot are collected by the vacuum system and separated. The concrete debris is collected in a dustbin located at the bottom of the machine, while the shot is separated for reuse by the unit. The depth of concrete abraded is determined by the rate of speed of the machine and the volume of shot fired into the blast chamber. The primary centrifugal shot blasting unit does not have the capacity to access the edges of walls or corners. In order to perform surface removal over the entire area, at least one additional piece of equipment would be required. The vacuum system provided by the vendor was not suitable for use in the nuclear environment. 


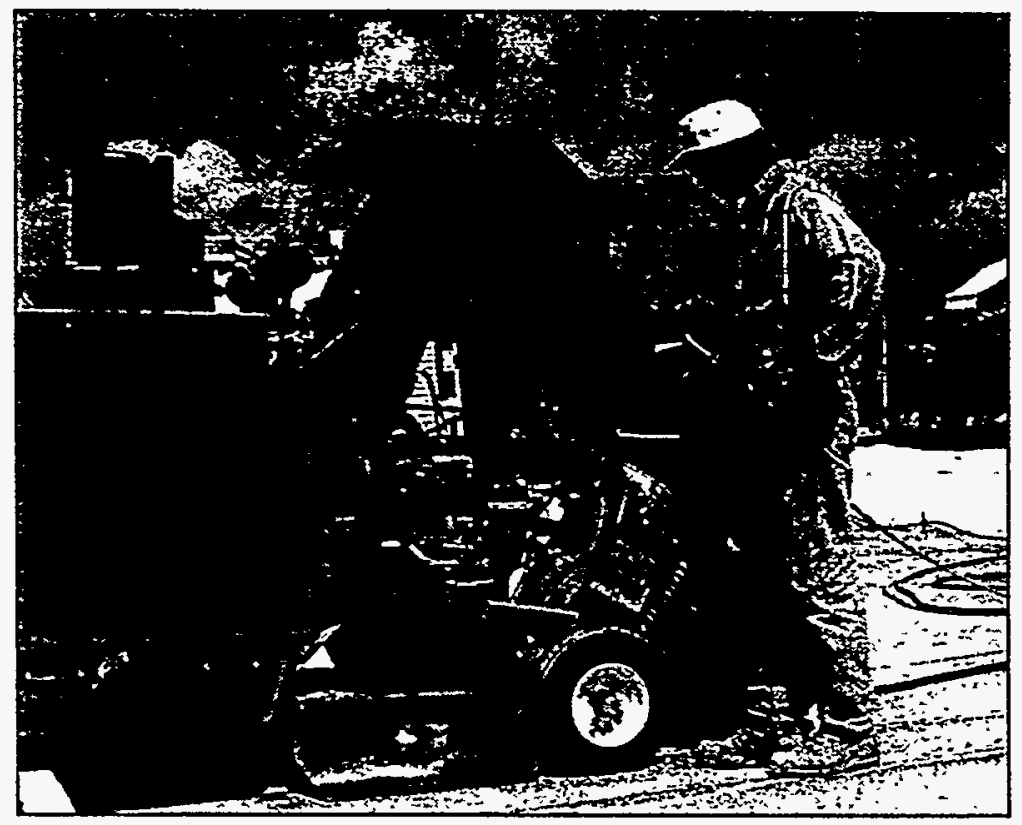

Figure 4. Centrifugal shot blasting technology.

\subsection{EMERGING CONCRETE REMOVAL TECHNOLOGIES}

Emerging decontamination technologies that may be capable of meeting FEMP's and DOE's remediation objectives include:

- Microwave scabbling;

- Flashlamp;

- Electro-hydraulic scabbling;

- Laser ablation;

- ROVCO2 Pellet System; and

- Liquid Nitrogen with Solid Particles Decontamination System.

The testing of these innovative technologies is being pursued as a different task. Testing these emerging technologies under identical conditions as the commercial technologies will provide direct comparable data on their performance.

\subsection{SURROGATE SELECTION AND PREPARATION}

A preliminary review of the types of concrete used at FEMP and other DOE sites indicates a wide variability in the composition of the concrete. This variability complicated the selection of the proper mix design for the construction of the concrete test areas. To facilitate the testing, a 4000-psi mix was specified. After the concrete had cured for 30 days, compression tests were performed, yielding a concrete compressive strength of $5700 \mathrm{psi}$. 
The coating selected was purchased from Michael A. Bruder \& Son (MAB) Architectural and Industrial Coatings. The concrete coating application specifications were to 1) apply Plymastic at 8 milliliters (mls) wet to obtain 7 mils dry film thickness; and 2) wait 24 hours, and then apply a finish of Plythane 880 coating at $3 \mathrm{mls}$ wet to obtain $1 \frac{1}{2} \mathrm{mls}$ dry film thickness. This coating is consistent with the type of acid resistant coating used throughout the FEMP site. The coating determination was made using FEMP's paint specifications for acid resistant surfaces.

Figure 5 depicts the test sections used for each technology. Each six-inch-thick concrete slab had an overall size of $20 \times 40 \mathrm{ft}$. One-half of the test section $(20 \times 20 \mathrm{ft}$.) was coated with an epoxy urethane coating. The other half of the test section consisted of uncoated concrete. A 6 in. dike surrounded each test section to aid in the evaluation of the technology's capacity to remove concrete at the interface of a floor and a wall. The concrete slab was 6 in. thick, whereas the dike was 4 in. thick. Figure 5 also illustrates the fully coated concrete slabs which will be used for the innovative coating removal technology testing.

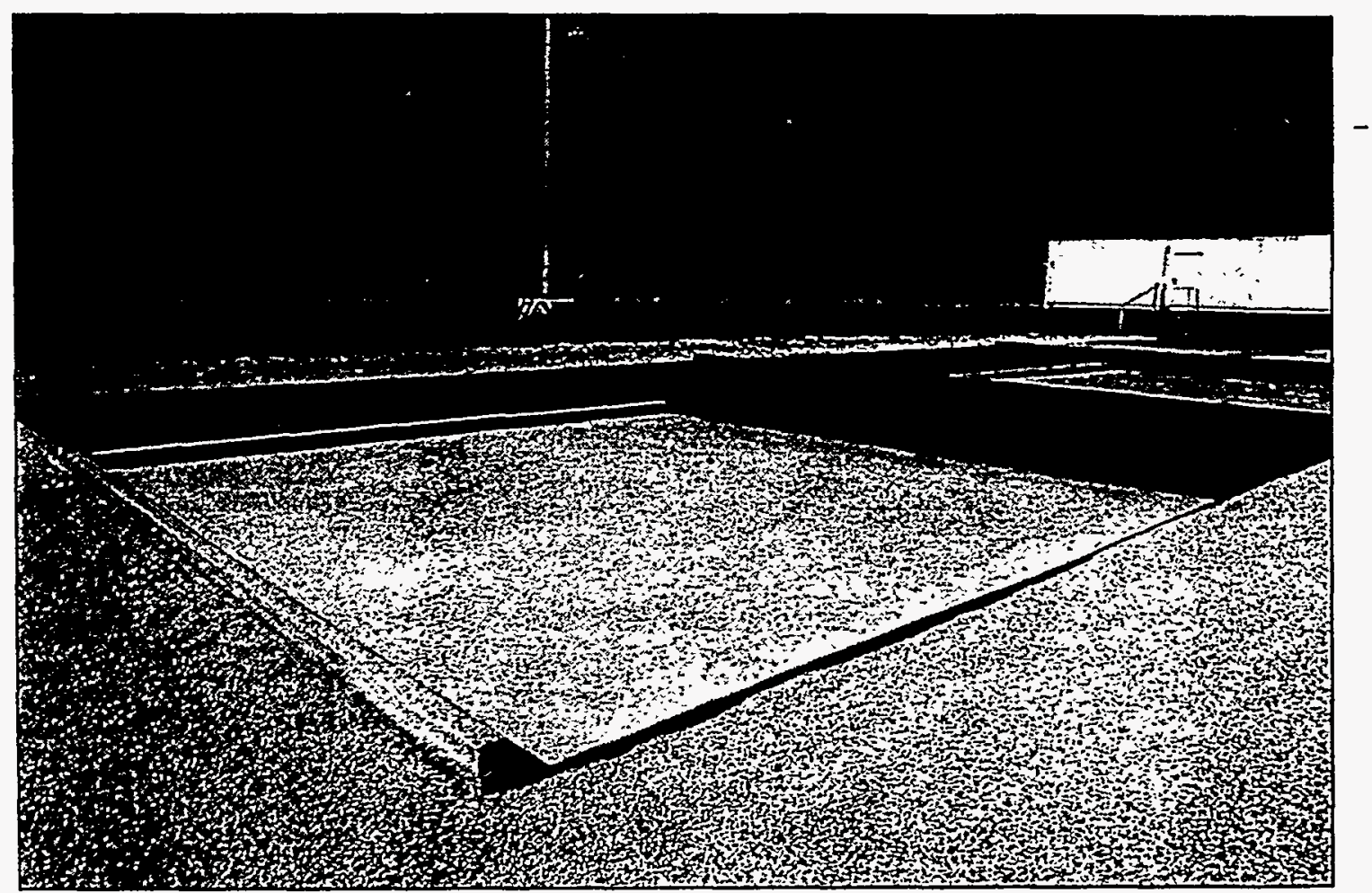

Figure 5. Individual test sections for each tẹchnology. 


\subsection{COMPARISON OF THE END POINTS ACHIEVED TO THE DECONTAMINATION OBJECTIVES}

Each technology was employed in the most efficient manner as determined by its vendor. The end point achieved was compared to the criteria of $1 / 4$ inch surface removal and/or 1 inch surface removal.

To facilitate the determination of the depth of removal, a State of Florida certified surveyor performed a 57-point survey of each test area prior to the technology assessments. Upon the conclusion of the testing, the surveyor completed a second survey of the same 57 points to determine the depth of removal. The final readings were subtracted from the initial readings and averaged over the 57 points to provide the average depth of removal. The accuracy of the surveying instrument was \pm 0.03 feet. The sensitivity of the measuring equipment was to $3 / 8$ inch, whereas the required surface removal was either $1 / 4$ inch or 1 inch. Measurement accuracy ranged from "not measurable" to approximately 50 percent. Thus, an accurate quantitative measurement to verify surface removed was not possible given the method employed during this testing. New measurement techniques should be developed and used to quantify the depth of surface removed.

The target removal depths for each of the technologies were the following:

- Milling:

$1 / 4 "$ (vendor information on capability)

- Steel grit vacuum blasting:

$1 / 4^{\prime \prime}$ (vendor information on capability)

- Ultra high pressure water:

$1 "$

- Scabbling:

$1 "$

- Centrifugal shot blasting:

$1 "$

\subsection{EXPERIMENTAL DESIGN AND PROCEDURES}

The testing of the selected technologies was conducted under the supervision of the Hemispheric Center for Environmental Technology (HCET) and the IUOE on the campus of Florida International University in Miami, Florida. Each technology was tested over a $20 \times 40 \mathrm{ft}$. floor area, including its ability to interface with a wall and the floor. Excluded from the test were items such as embedded plates, cut-off bolts and pipes, sloped floors, or construction joints. Although excluded from the tests, surface removal on/around such items would most likely increase the effort, thus decreasing the production rate for each technology tested.

The $20 \times 40 \mathrm{ft}$. area provided sufficient time to collect the operational and safety information. The experimental design consisted of the following:

- Methods for identifying technology vendors;

- Test location and utility parameters; and

- Data requirements. 


\subsubsection{Identification of Commercial Technology Vendors}

The request for prospective bidders was advertised in the Commerce Business Daily (CBD). The advertisement identified the type of work to be contracted and the minimum qualifications for bidders. Qualified and interested bidders were asked to submit an expression of interest. The purpose of the advertisement was to pre-qualify prospective bidders by evaluating their response to the request to determine whether they could indeed meet the qualification standards. The qualifications for the bidders included the number of years' work experience in nuclear decontamination and references of previous work performed using the proposed technology.

Following the bid opening, the bids were reviewed to ensure that the lowest apparent bidder would be responsive and responsible. Determination of responsiveness was based on proper completion of bid forms and the acknowledgment of any amendments to the invitation for bid. The lowest apparent bidder was deemed responsible if this bidder possessed the capability and experience required in the solicitation to perform the test at the bid price in a safe and timely manner.

\subsubsection{Test Location and Utility Parameters}

The test location consisted of a series of concrete pads six inches thick surrounded by a 6 in. dike on three sides of each test area. Adjacent to the pads was a trailer, which served as a field office, changing facility, and a cool-down area for the technologists and the technology assessment team. A fence restricting access to the area surrounded the trailer and the pads.

The pads were exposed to the environment with one exception. A $20 \times 20 \mathrm{ft}$. tent with four sides was erected over one-half of the concrete pad. This tent served as a wind buffer during the collection of dust samples by the IUOE. After the completion of the health and safety portion of the testing, the technologists had the option of using the tent to protect personnel and equipment from the elements. This tent was used for all but the milling technology assessment.

A 60-psi, 60-gallon-per-minute water supply and a 110-volt, 15-amp electric supply was available for use by the vendors. The vendors provided any other utilities (e.g., 220- or 480-volt electricity, diesel fuel, compressed air, etc.).

\subsubsection{Test Equipment, Personnel, and Materials}

The Hemispheric Center for Environmental Technology and the International Union of Operating Engineers supplied:

- Light-duty fork lift;

- 60-psi, 60-gallon-per-minute portable water supply and a 110-volt 15-amp electric supply;

- Surrogate materials;

- Monitoring instrumentation;

- Project oversight; and

- Sample and data collectors.

The technology vendor was required, per the subcontract, to supply the following: 
- All equipment and support equipment required;

- Job safety analysis for each technology;

- Operating procedures;

- Blast media and other materials;

- Trained operators;

- Project manager;

- Information required to complete the data requirements section;

- Transportation of all equipment, materials, and personnel to FIU; and

- Per diem for all vendor personnel.

\subsection{DÁTA REQUIREMENTS AND SAMPLE COLLECTION METHOD}

Information was collected through personal communication with vendors and technologists, vendor-supplied literature, and field testing. Time studies were conducted to collect some of the operational data.

Field measurements were taken to document potential personnel exposure and other measurable data requirements. Documentation provided by the vendors and interviews with the vendors provided other pertinent information. Table 1 details the data requirements and the sample collection methods.

The technology vendor was responsible for determining and providing information to FIU-HCET related to the characterization of the waste stream. The vendors were provided material safety data sheets on the paint products used in the development of the surrogates to aid in the characterization determination. FIU-HCET was responsible for the management and disposal of the generated waste.

Table 1.

Data Requirements and Sample Collection Methods

\begin{tabular}{|l|l|}
\hline \multicolumn{1}{|c|}{ Data Requirements } & \multicolumn{1}{c|}{ Sample Collection Methods } \\
\hline & General Information \\
\hline Technology description & Vendor supplied; field inspection \\
\hline Equipment requirements & Vendor supplied; field verification \\
\hline Vendor information & Vendor supplied \\
\hline \multicolumn{2}{|c|}{ Cost Data } \\
\hline Capital cost for the purchase of equipment & Vendor supplied \\
\hline Media costs & Vendor supplied \\
\hline
\end{tabular}


Table 1.

Data Requirements and Sample Collection Methods (Continued)

\begin{tabular}{|l|l|}
\hline \multicolumn{2}{|c|}{ Operational Data } \\
\hline Production ratés & Time studies \\
\hline End point achieved & Field measurement \\
\hline Labor classification & Vendor supplied; field verification \\
\hline Benefits & Vendor supplied; field verification \\
\hline Limitations & Vendor supplied; field inspection \\
\hline Utility requirements & Vendor supplied; field verification \\
\hline Environmental conditions & Vendor supplied; field inspection \\
\hline Waste management & Vendor supplied; field inspection \\
\hline \multicolumn{1}{|c|}{ Characteristics of waste } & Field observation \\
\hline \multicolumn{1}{|c|}{ Quantity of media used } & Field calculation \\
\hline Characteristics of media & Media material safety data sheet \\
\hline Equipment portability & Vendor supplied; field verification \\
\hline Operation/maintenance requirements & Vendor supplied; field verification \\
\hline \multicolumn{2}{|c|}{ Implementation Data } \\
\hline Level of training required & Vendor supplied \\
\hline Availability of equipment and supplies & Vendor supplied; verification \\
\hline Health and safety & Vendor and IUOE* supplied \\
\hline \hline
\end{tabular}

International Union of Operating Engineers 


\section{DEVIATIONS}

The goal of this assessment was to identify technologies that can be applied directly to nuclear environments. This goal was met by the ultra high pressure water and scabbling technologies. In the case of the centrifugal shot blaster, however, this goal was not met during field testing.

The centrifugal shot blasting equipment lacked a nuclear vacuum system. Moreover, the method of emptying the dust collection hopper is not a normally accepted practice in a nuclear environment. This technology also lacked the equipment for the floor/wall interface and failed to allow access to within 8 to 10 inches of the edge of the slab, requiring the use of an additional technology for completion of the surface removal. Thus, the surveyor's perimeter points were not used in calculating the average depth of removal for the centrifugal shot blasting technology. During the course of this study, it could not be verified whether this centrifugal shot blasting technology vendor markets a nuclear compatible system. The system modifications required to meet radiological control good management practices would not require an equipment redesign; nonetheless, equipment-specific modifications would be required.

The vendors were required to optimize the use of their technologies over the $20 \times 40 \mathrm{ft}$. area and remove the concrete to the depth required. In some cases, multiple pieces of equipment were used to achieve the project objectives. The project team set out to determine the operational issues related to each individual piece of equipment. In the case of the Pentek equipment, the project team did not consider that the Squirrel I ${ }^{\circledR}$, Squirrel III ${ }^{\otimes}$, and Corner-Cutter ${ }^{\otimes}$ had been operated over a significant enough area or time to develop defensible performance data. In addition, Pentek demonstrated the performance of two MOOSE ${ }^{\circledR}$ scabblers, each equipped with different types of scabbling bit-one with a standard nine tooth bit and the other with a more aggressive cross-point bit design. Consequently, a technology termed the "Pentek Combination" was assembled, and its overall production rate was calculated using production data from the MOOSE $^{\circledast}$ scabblers, the Squirrel $I^{\circledast}$, Squirrel III ${ }^{\circledR}$, and the Corner-Cutter ${ }^{\circledR}$. 


\section{TECHNOLOGY RECOMMENDATIONS}

The intent of this section is to review the performance of the technologies tested and make recommendations as to ways to improve them based on the test results. It is important to note that while the recommended modifications may improve the system in one area of operation, they may adversely impact the technology's ability to excel in other areas.

In the case of all the technologies tested, no feedback was provided by the technology itself regarding the depth of removal achieved. In most cases, a 2 in. $\times 4$ in. piece of lumber was utilized during application to estimate the depth of removal. This method was inaccurate. It would be convenient to incorporate an immediate feedback system into the technology to inform the operator when the desired depth or residual contamination levels were reached.

\subsection{ULTRA HIGH PRESSURE WATER}

In order to apply ultra high pressure water in a radiological environment, a specially designed enclosure may be required to collect the waste water, which could be treated for later release or reuse. This specially designed enclosure would also require an adequate air exchange system to maintain good visibility inside the enclosure. Moreover, adequate personal protection equipment (PPE) would have to be used since it was observed that water splashed on the operator.

This technology was effective for coating removal; however, the scarification of the concrete left a very uneven surface due to the fact the technology attacked the mortar in the concrete. In addition, as the mortar was removed, the aggregate would fly off, producing a projectile hazard. This type of end-surface finish would be difficult to survey in a radiological environment because of all of the crevasses created by the removal of the mortar. Various pressures, vacuum shrouds, the use of abrasives may increase the viability of this technology for surface removal. The configuration of the wand placed stress on the operator, increasing operator fatigue. Hence, the design of the wand should be reviewed from an ergonomic perspective to reduce operator strain.

\subsection{SCABBLING}

The scabbling technology tested utilized the MOOSE ${ }^{\circledast}$, Squirrel $\mathrm{I}^{\circledR}$, Squirrel $\mathrm{III}^{\circledR}$, and the CornerCutter $^{\circledR}$. This particular technology exhibited a large amount of mechanical vibration inherent to the system (with the exception of the Squirrel $\mathrm{III}^{\circledR}$ ), requiring periodic tightening of bolts and piping connections. It would be advantageous to develop a method to reduce the amount of periodic maintenance.

The shroud worked more effectively when the technology was used in the direction in which the material moved toward the single vacuum connection. When the technology was operated in the opposite direction, the shroud provided minimal pickup. Thus, the shroud requires redesign for conditions in which the material is to be picked up in both directions of operation.

The Squirrel $\mathrm{III}^{\oplus}$ provides a means of reducing the mechanical vibration the operator is exposed to by using a pin connection. However, the Squirrel $I^{\mathbb{D}}$ and the needle gun are operated with the 
operator directly over the tool, increasing the potential exposure to mechanical vibration. This combination exposes the operator to high levels of fatigue. The design of the hand-held unit should be reviewed from an ergonomic perspective to reduce operator strain.

\subsection{CENTRIFUGAL SHOT BLASTING}

The centrifugal shot blasting technology requires an integral HEPA vacuum system to meet the U.S. DOE's radiological controls requirements [4]. The method implemented to empty the dust hopper involved the use of a shovel, which has the potential of generating airborne contamination. A waste drum collection system that reduces the chances of airborne contamination and is not as labor intensive is therefore required to prepare this technology for practical application in the nuclear environment.

The system tested failed to reach closer than 8 to 10 inches from the edge of the pad or dike. Thus, additional equipment is required to complete the task of removing concrete on the entire pad adjacent to the dike and the edge of the pad. This may include additional shot blasting equipment or other types of equipment.

The system tested produced an uneven surface from one side of the cut to the other. This was discussed with the technology vendor, and it was determined that the "hot spot" required adjustment. This adjustment did not completely eliminate the problem, however. A method employed by other centrifugal shot blasting manufacturers is to use a steel plate under the blast head to determine and then adjust the blast pattern. The steel plate provides better feedback on the location of the hot spot to enable the proper adjustment. 


\section{LESSONS LEARNED}

The technology assessment process was performed outdoors, exposing the equipment and operators to adverse environmental conditions, including wind and rain. To minimize the impact of the wind and rain, a $20 \times 20 \mathrm{ft}$. fabric tent was erected over half of the concrete test slab. Four sides of the tent were lowered and secured during dust and sound monitoring. However, the tent did not provide a wind-tight environment, potentially skewing the dust monitoring data collected. The acoustical properties of the tent were not similar to those of a typical building construction found in the DOE Complex. This lack of similarity potentially skews the noise monitoring data collected. In future projects, the requirements for achieving reliable dust and sound measurements should be reviewed.

The vendors were required to optimize the use of their technologies over the $20 \times 40 \mathrm{ft}$. area to remove concrete to the depth required. In some cases, multiple pieces of equipment were used to achieve the project objectives. The project team set out to determine the production rates and waste management issues related to each individual piece of equipment. In the case of the Pentek equipment, the project team did not consider that the Squirrel $\mathrm{I}^{\oplus}$, Squirrel $\mathrm{III}^{\circledR}$, and needle gun were operated over a significant enough area or time duration to develop defensible performance data. Consequently, a technology termed the "Pentek Combination" was developed, and its overall production rate was calculated. For future testing, the requirement of using an individual piece of equipment over a significant area and for a significant amount of time will be reviewed in order to collect this individual performance data.

The individual technologies tested employed various methods to collect the material generated during the concrete removal operations (In the case of ultra high pressure water, the material generated was not collected). The variety of methods used to collect the material, the differences in density of the material removed, and in some cases, the spent media provided an inconsistent approach in determining the volume of the material removed. These variations included the amount of free board in a given waste drum. In the case. of actual field operations, it is anticipated that the waste drums would be loaded directly into a disposal container. In this case, the exterior volume of the collection drum would be used to determine the volume required for disposal. A more systematic approach for determining the waste volume generated, including counting the number of drums and determining the exterior volume of the drum, is needed to ensure that the numbers are directly comparable.

In the evaluation of the centrifugal shot blasting technology, nuclear systems were not used. These non-nuclear systems could potentially skew the data generated in the areas of dust monitoring and production capabilities of the equipment. Moreover, a piece of equipment needed to perform removal operation adjacent to the wall was not available for the evaluation of the centrifugal shot blasting technology. The evaluation of the impact of using a non-nuclear system is required on a case-by-case basis to determine whether the use of a non-nuclear system invalidates the data collected. Vendors must be aware of project goals and fully comply with the project objectives. 


\section{REFERENCES}

1. Fernald Environmental Restoration Management Corporation (FERMCO), 1995. Operable Unit 3 Remedial Design/Remedial Action Work Plan for Interim Remedial Action, Final, U.S. Department of Energy.

2. Fernald Environmental Restoration Management Corporation (FERMCO), 1993, Operable Unit 3 Remedial Investigation and Feasibility Study Work Plan Addendum, Final, U.S. Department of Energy.

3. U.S. Department of Energy, August 1995, Contaminated Concrete: Occurrence and Emerging Technologies for DOE Decontamination, DOE/ORO/2034.

4. U.S. Department of Energy, 1990, Radiation Protection of the Public and the Environment, DOE Order 5400.5, Office of Environment, Safety, and Health, Washington, D.C.

5. U.S. Department of Energy, 1994, Decommissioning Handbook, DOE/EM-0142P.

6. Oak Ridge National Laboratory (ORNL), 1993, Oak Ridge National Laboratory Technology Logic Diagram, ORNL/M-2752, U.S. Department of Energy.

7. Idaho National Engineering Laboratory (INEL), January 1994, Idaho National Engineering Laboratory Decontamination and Decommissioning Technology Logic Diagrams, U.S. DOE, EGG-WTb-11104.

8. Fernald Environmental Restoration Management Corporation (FERMCO), 1994, Operable Unite 3 Treatability Study Work Plan, FERMCO, Cincinnati.

9. Fernald Environmental Restoration Management Corporation (FERMCO), 1995, Operable Unit 3 Remedial Design Remedial Design Prioritization and Sequencing Report, Final, U.S. Department of Energy. 


\section{APPENDIX A}

\section{TECHNOLOGY DATA REQUIREMENTS: DEFINITIONS}

Following is an explanation of the information presented in tabular form in Appendixes B and C. These tables present a summary of the technologies tested, with Appendix B listing the data requirements for ultra high pressure water, centrifugal shot blast, and scabbling technologies, and Appendix $\mathrm{C}$ listing the data requirements for the milling and steel grit vacuum blasting technologies. The information is organized in Technology Overview tables, followed by Utility/Media Requirement tables, and Vendor Data tables. The text below describes each of these tables and their elements.

\section{TECHNOLOGY OVERVIEW TABLES}

The technologies shown in Tables B.1, B.2, C.1, and C.2 are described in terms of operating principles and equipment used. Technology class name, technology description, estimated capital cost, benefits, limitations, production rate, labor classification, environmental conditions, characteristics of waste and support equipment are described in the technology overview tables.

\section{Technology Class}

Established databases were used for categorizing and performing the initial screening of technology types. These databases provided a screening based on the applicability of a technology to a given material and contaminant. These databases included:

- DOE/EM-0142P Decommissioning Handbook [5];

- ORNL/M-2751 Oak Ridge National Laboratory Technology Logic Diagram [6];

- EGG-WTD-11104 Idaho National Engineering Laboratory Decontamination and Decommissioning Technology Logic Diagram [7]; .

- DOE/ORO/2034 Contaminated Concrete: Occurrence and Emerging Technologies for DOE Decontamination [3];

- Fernald Environmental Restoration Management Corporation (FERMCO), 1994; Operable Unit 3 Treatability Study Work Plan, FERMCO, Cincinnati [8];

- Remedial Action Program Information Center (RAPIC) database; and

- Fernald Environmental Restoration Management Corporation (FERMCO), 1993, Operable Unit 3 Remedial Investigation and Feasiblity Study Work Plan Addendum, Final, U.S. Department of Energy [2]. 


\section{Technology Description}

The technology class description provides an introduction to the broad technology category. Details such as a description of the media used, how the media are propelled, the vacuum system (if used), and the process by which the paint/contaminant is removed are provided.

\section{Estimated Capital Cost}

Capital cost represents the purchase cost of the technologies tested. These figures were obtained from the technology vendors.

\section{Benefits}

Benefits were obtained by performing a literature search of the individual technologies and conducting field demonstrations. If a conflict existed between published information and the field demonstrations, the data observed in the field testing were used. This section provides an overview of the potential benefits.

\section{Limitations}

Limitations were obtained by performing a literature search of the individual technologies and conducting field demonstrations. If a conflict existed between published information and the field demonstrations, the data observed in the field testing were used. This section provides an overview of the potential limitations.

\section{Production Rate}

The number of square feet of the concrete pad was divided by the number of hours required to finish the entire $20 \times 40 \mathrm{ft}$. slab. Normal maintenance activities are included in these operating hours. If a major equipment failure occurred, the time required to complete this major repair is not included in the calculation of the production rate.

\section{Labor Classification}

Standard labor classifications are used to determine the personnel required. These classifications are equipment operators, technicians, and field engineers. This represents the minimum number of personnel required to operate the equipment. The extrapolation of the labor required to operate the equipment in a contaminated environment is not included. 


\section{Environmental Conditions}

A description of the work environment created by the operation of the technology is provided. These descriptions include presence or absence of visible emissions, water fog created in enclosure, visible air turbulence, and so forth.

\section{Characteristics of Waste}

This section describes the physical condition of the secondary waste as determined by visual observation. These observations include: 1) fine powder with no observable difference from the media and the concrete and 2) small pieces of media mixed with concrete.

\section{Support Equipment}

This section provides an overview of the major piece of equipment required to support the operation of the technology.

\section{UTILITY/MEDIA REQUIREMENT TABLES}

Tables B.4 and C.3 describe the end point achieved, media type, media quantity, utility requirements, operation and maintenance requirements, availability of equipment and equipment. Vendor information was also used and verified by field measurements.

\section{Technology Class}

The technology class description provides an introduction to the broad technology category. Details such as a description of the media used and of the vacuum system (if any), how the media are propelled, and the process by which the paint/contaminant is removed are provided.

\section{Technology Name}

The specific name of the technology as obtained from the vendor is provided.

\section{End Point Achieved}

The end point achieved by the technology is described under this category. The options for this category are coating removal, $<1 / 4$-inch removal, and $>1 / 2$-inch $<1$-inch removal.

\section{Media Type}

This section presents the general classification of the media used. Specific grades of media are not recorded. The type of media varied with the required depth of removal and the required surface finish. 


\section{Media Cost}

Vendor information was used to determine the cost of the media per pound. In the case of the technologies that use bits, the cost for a complete bit replacement was divided by the number of operating hours required before bit replacement. The bit replacement cost and the number of operating hours required before bit replacement were obtained from the vendor.

\section{Media Quantity}

The quantity of media required per hour of operation was obtained from the vendor.

\section{Utility Requirements}

The types of utilities required to operate the technology are presented in this section. The utilities used during the field testing are shown. In many cases, optional power sources are available for each type of equipment. Utilities needed to operate the containment and ventilation system or any support equipment are not shown in the tables.

\section{Operating/Maintenance Requirements}

The operational/maintenance requirements provide an account of the types of operational and maintenance activities performed during the hours of operation.

\section{Availability of Equipment}

The availability of equipment and supplies was obtained from the individual technology vendors. Long-lead procurement items are differentiated from equipment and supplies that are off-the-shelf items.

\section{Equipment Portability}

Equipment portability is broken down into four categories. These categories include equipment that can be moved by one person; equipment that requires two people to move; equipment that requires a forklift to move; or trailer-mounted equipment.

\section{VENDOR DATA TABLES}

Tables B.5 and C. 4 provide a list of the vendors that participated in this study. The technology name, company name, address, phone and fax numbers, and type of services are provided.

\section{Vendor Name}

Company name. 


\section{Address, Phone and Fax numbers}

This section provides the address and phone and fax number of the company that performed the demonstration.

\section{Services}

This section details the type of services provided by the company. The three types of services are service provider, equipment provider, or service and equipment provider.

\section{HEALTH AND SAFETY ISSUES}

A separate report is available from the International Union of Operating Engineers related to the health and safety issues of the technologies. Please contact the IUOE at 304-253-8674 to obtain this report. 
DATA REQUIREMENTS FOR ULTRA HIGH PRESSURE WATER, CENTRIFUGAL SHOT BLAST, AND SCABBLING 


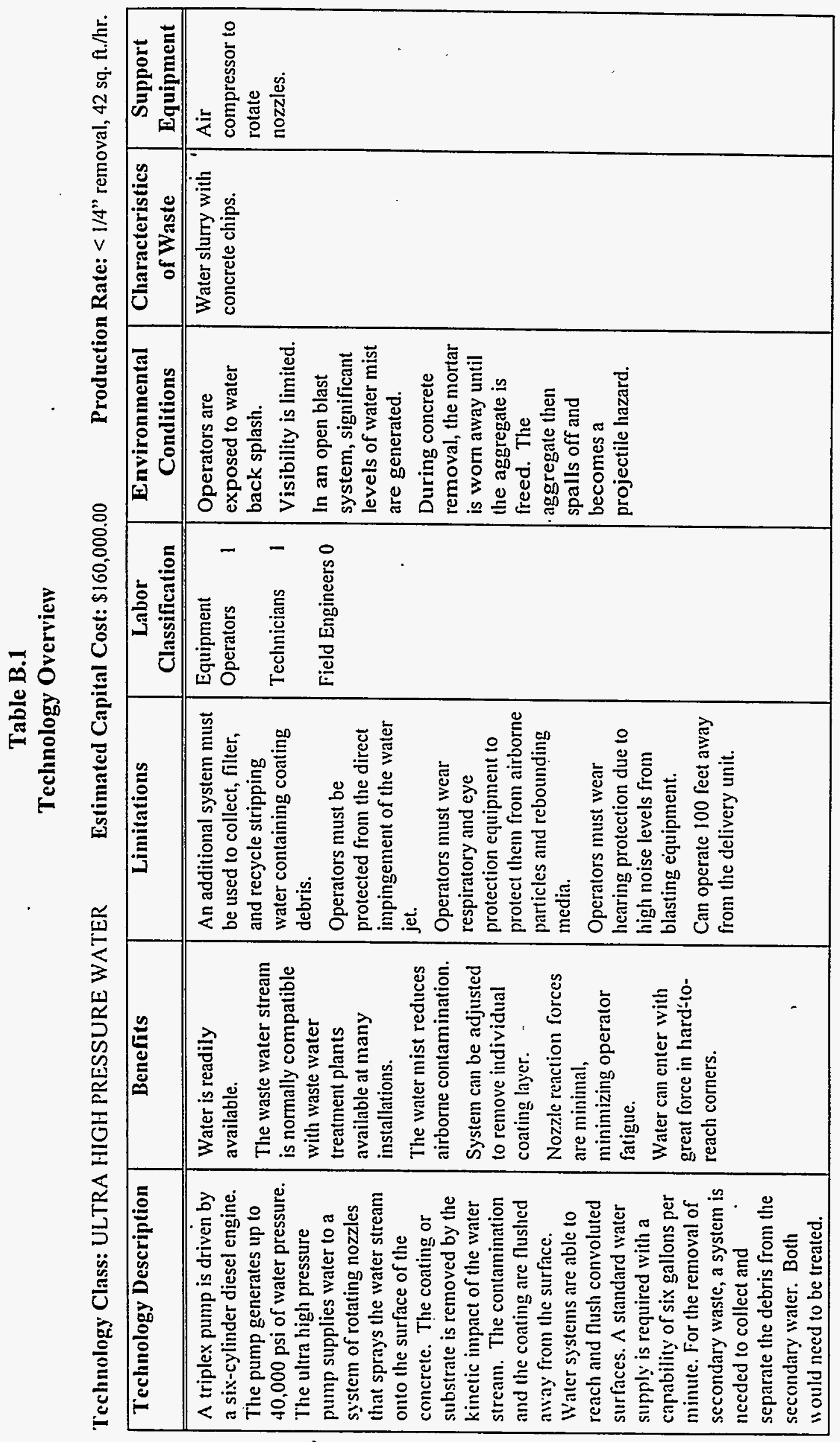




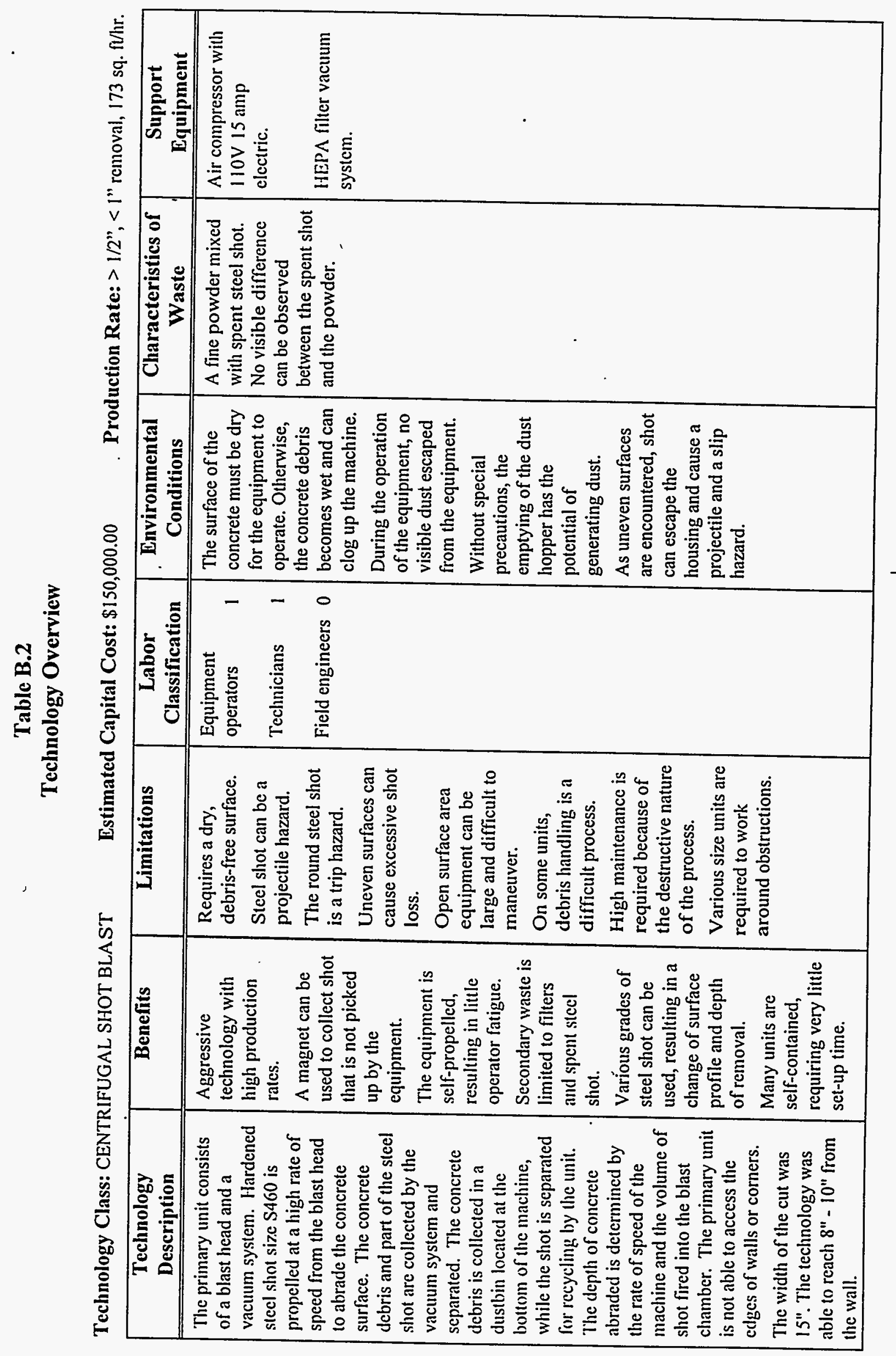




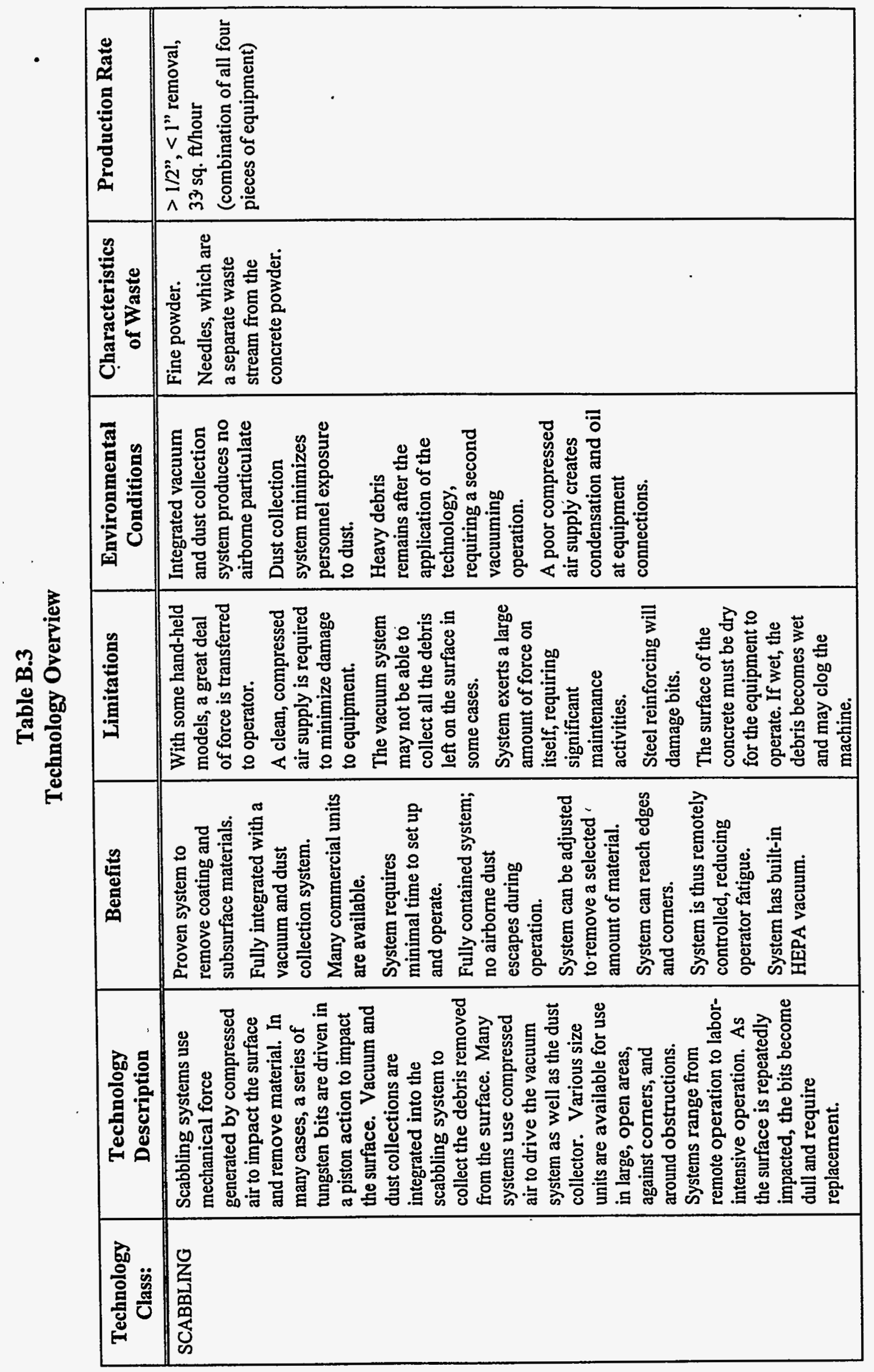




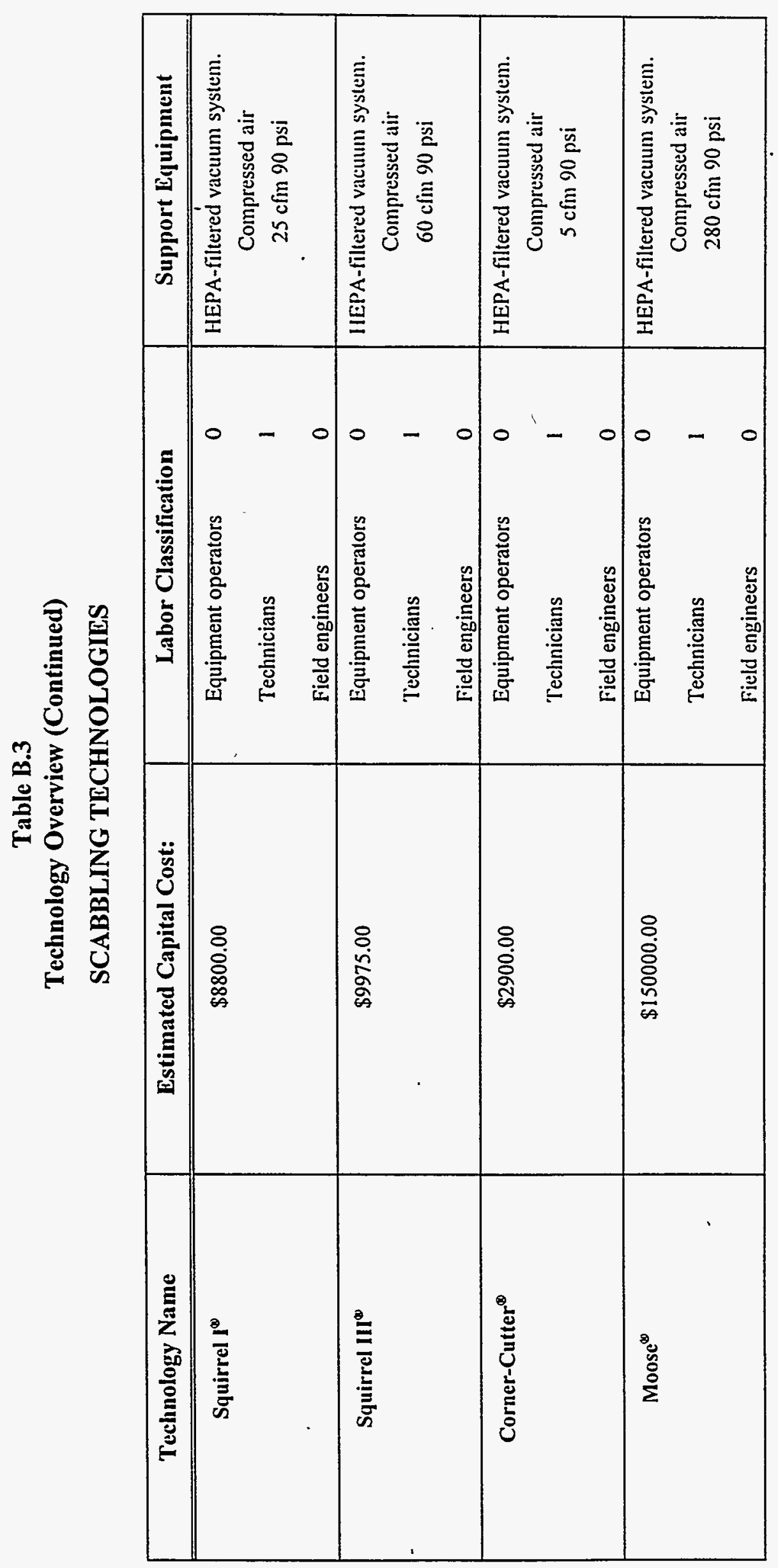




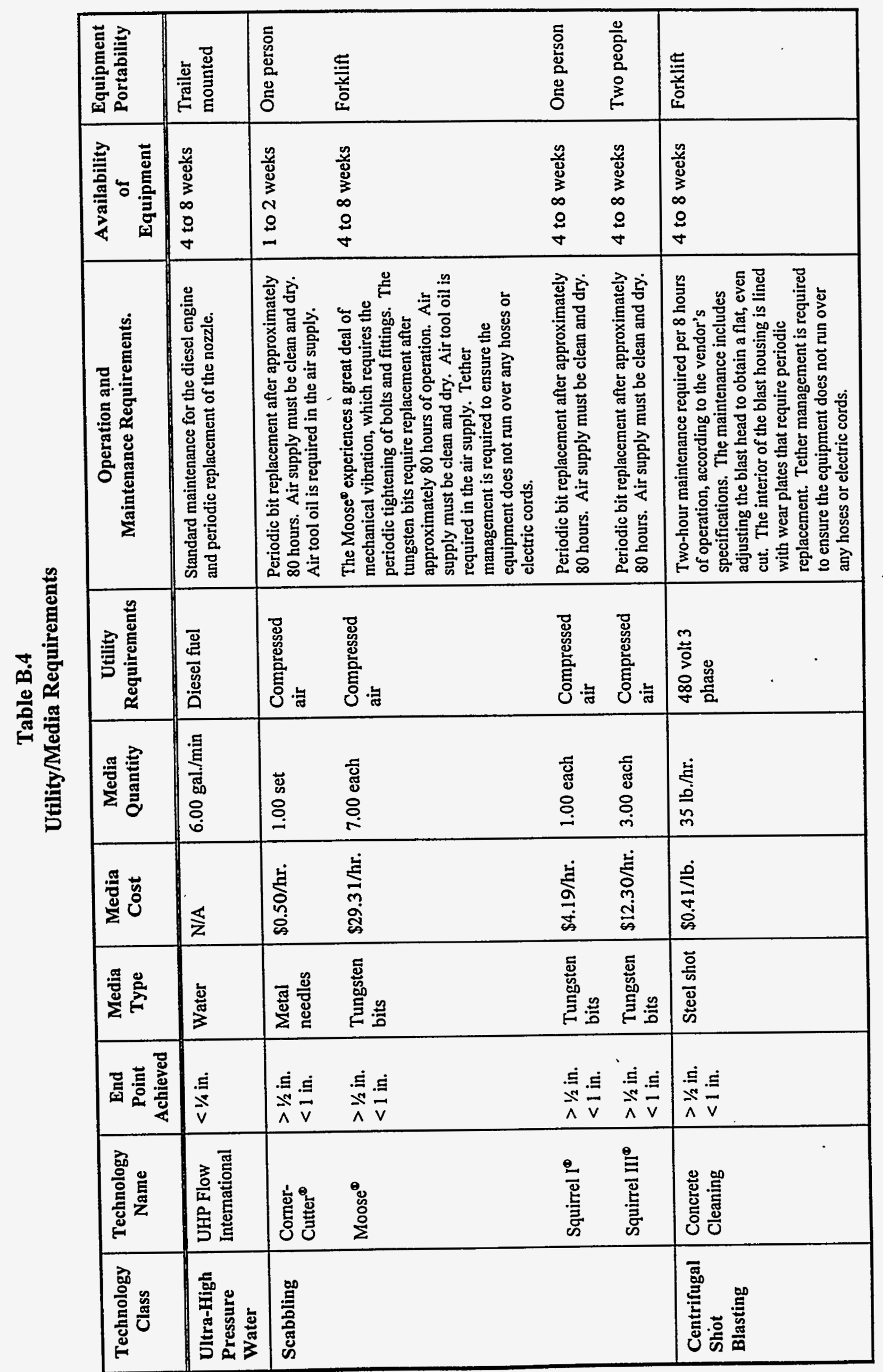


Table B.5

Vendor Data

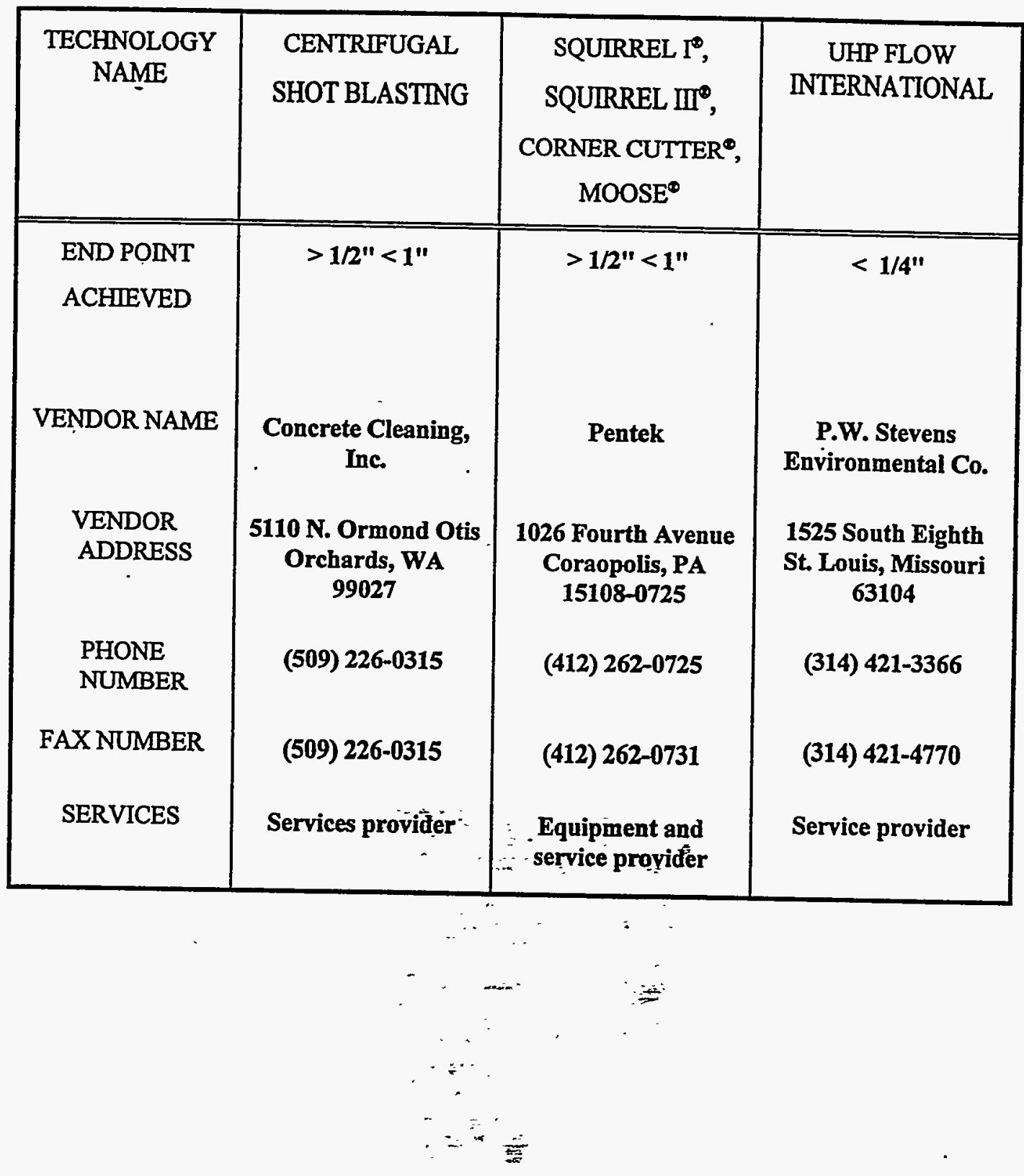




\section{DATA REQUIREMENTS}

FOR MILLING AND STEEL GRIT VACUUM BLASTING 


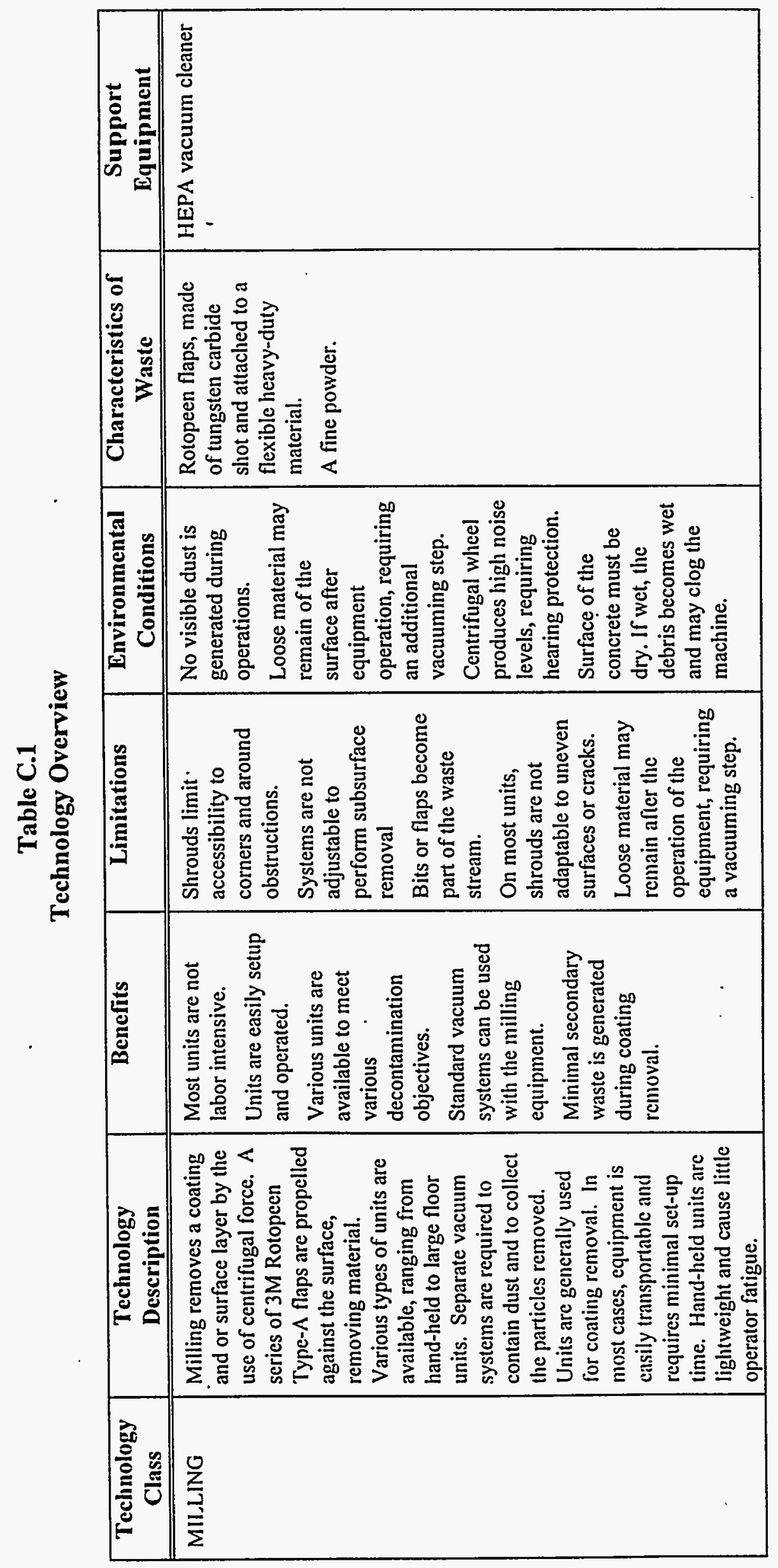




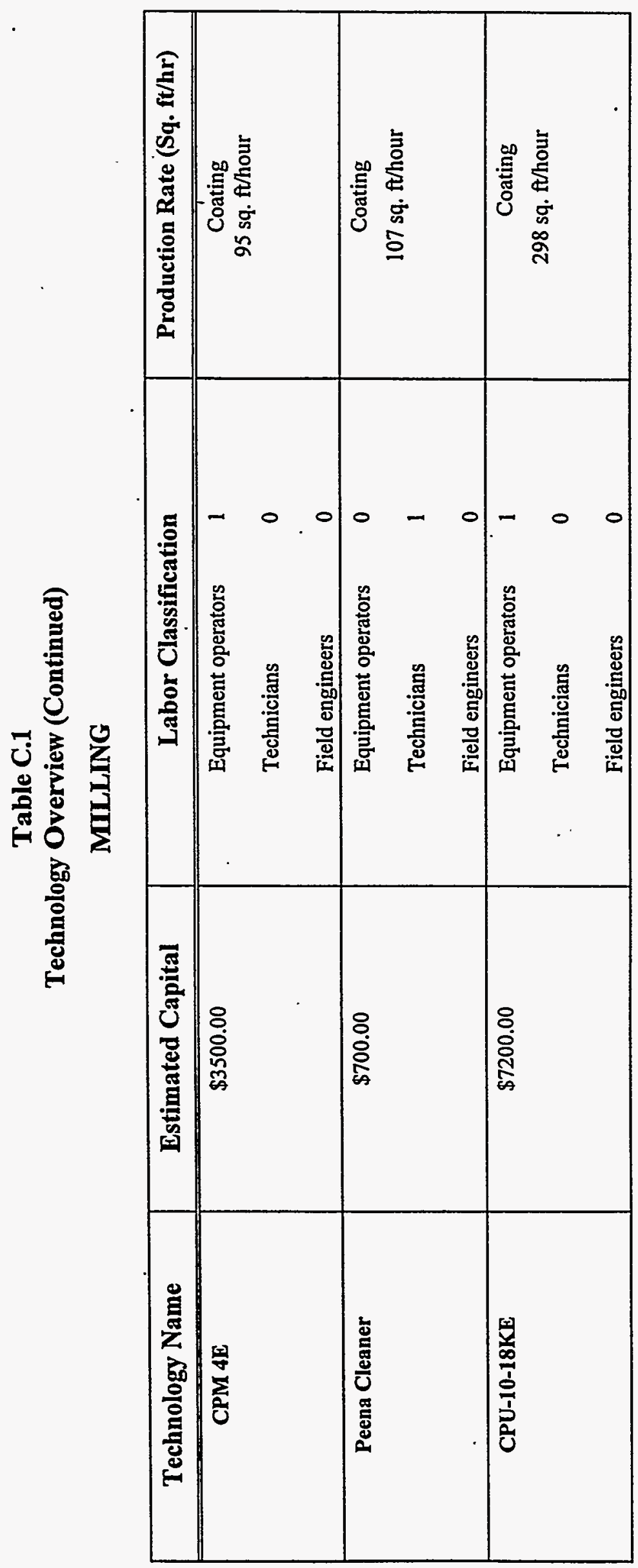




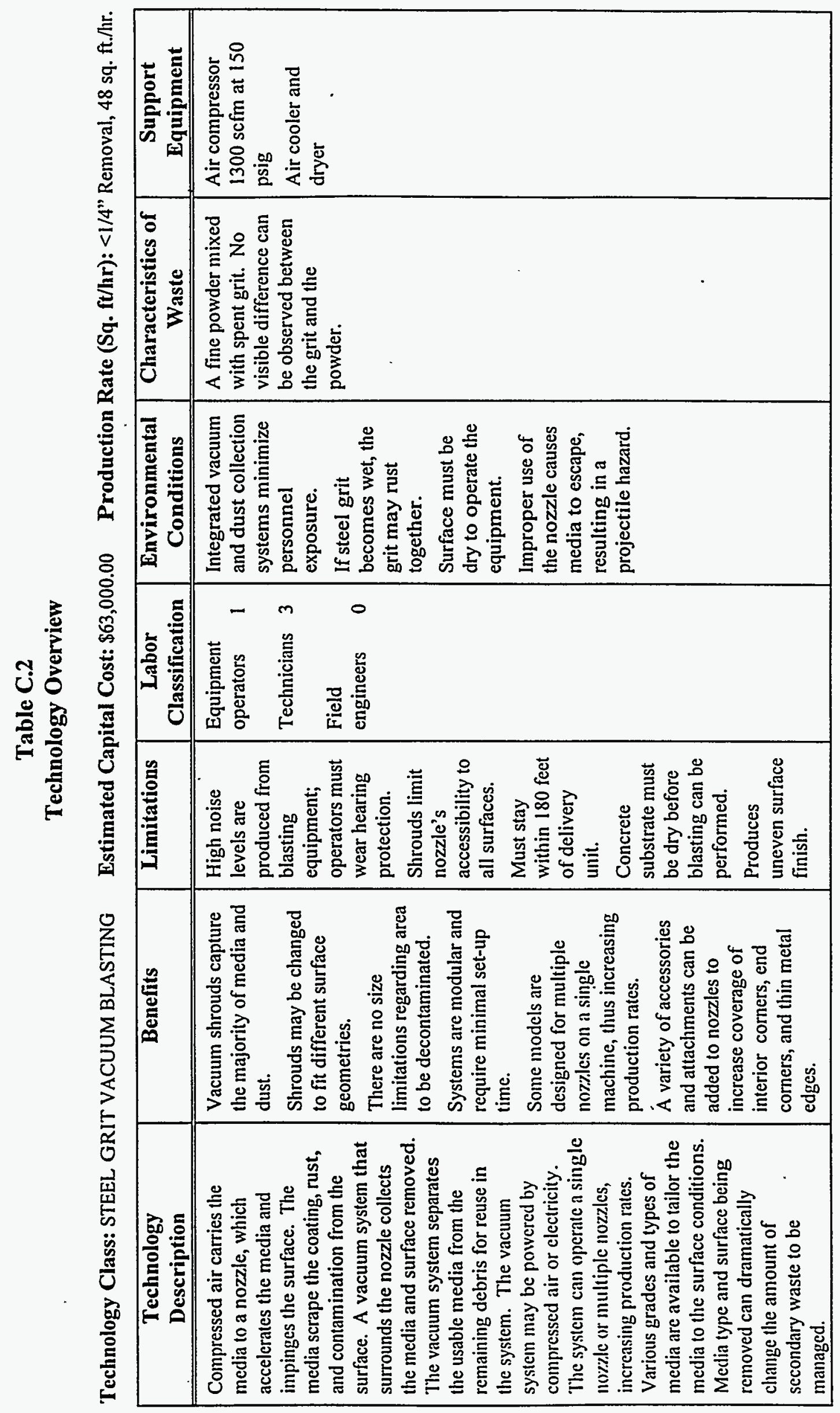




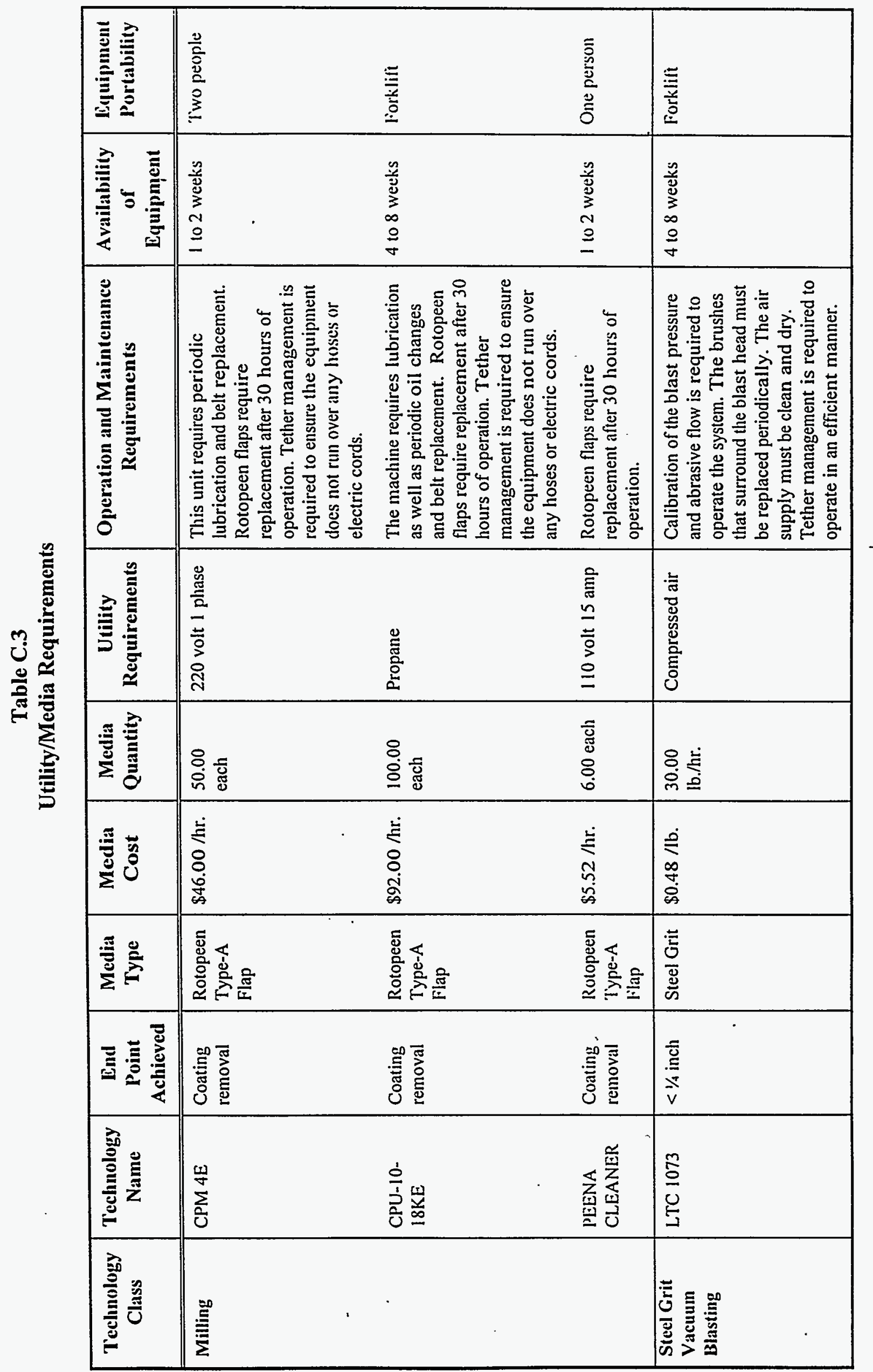


Table C.4

Vendor Data

\begin{tabular}{|c|c|c|c|}
\hline $\begin{array}{l}\text { TECHNOLOGY } \\
\text { NAME }\end{array}$ & $\begin{array}{c}\text { CPM 4E }, \\
\text { CPU-10-18KE }\end{array}$ & PEENA CLEANER & LTC 1073 \\
\hline $\begin{array}{l}\text { END POINT } \\
\text { ACHIEVED }\end{array}$ & Coating Removal & Coating Removal & $<1 / 4$ inch \\
\hline VENDOR NAME & EDCO & Unique Systems & LTC AMERICAS \\
\hline $\begin{array}{l}\text { VENDOR } \\
\text { ADDRESS }\end{array}$ & $\begin{array}{l}100 \text { Thomas Johnson } \\
\text { Fredrick, MD } 21702\end{array}$ & $\begin{array}{c}2929175 \text { Street } \\
\text { P.O. Box } 342 \\
\text { Lancing, IL } 60438\end{array}$ & $\begin{array}{l}22446 \text { Davis Drive } \\
\text { Suite 142, } \\
\text { Sterling, VA 2016 }\end{array}$ \\
\hline $\begin{array}{l}\text { PHONE } \\
\text { NUMBER }\end{array}$ & (800) 447-3326 & $(800)$ 536-7711 & (800) 822-2332 \\
\hline FAX NUMBER & (301) 663-1600 & (708) 418-1089 & (703) 406-4523 \\
\hline SERVICES & Equipment provider & $\begin{array}{l}\text { Equipment } \\
\text { provider }\end{array}$ & $\begin{array}{l}\text { Equipment and } \\
\text { service provider }\end{array}$ \\
\hline
\end{tabular}




\section{MILLING AND STEEL GRIT VACUUM BLASTING TECHNOLOGIES}

Following are descriptions and recommendations for improvements of the milling and steel grit vacuum blasting technologies.

\section{D.1 TECHNOLOGY DESCRIPTIONS}

The following two paragraphs and pictures present information related to the milling and steel grit vacuum blasting technologies.

\section{D.1.1 Milling}

Milling is a technology that removes coating and or surface layer by the use of centrifugal force. Series of $3 \mathrm{M}$ Rotopeen Type-A flaps are propelled against the surface removing material. Various types of units are available, ranging from hand-held units to large floor units. Separate vacuum systems are required to contain the dust and collect the particles removed. Units are available in gasoline, propane, and various electrical supplies. In most cases, equipment is easily transportable and requires minimal set-up time. Hand-held units are lightweight and cause little operator fatigue.

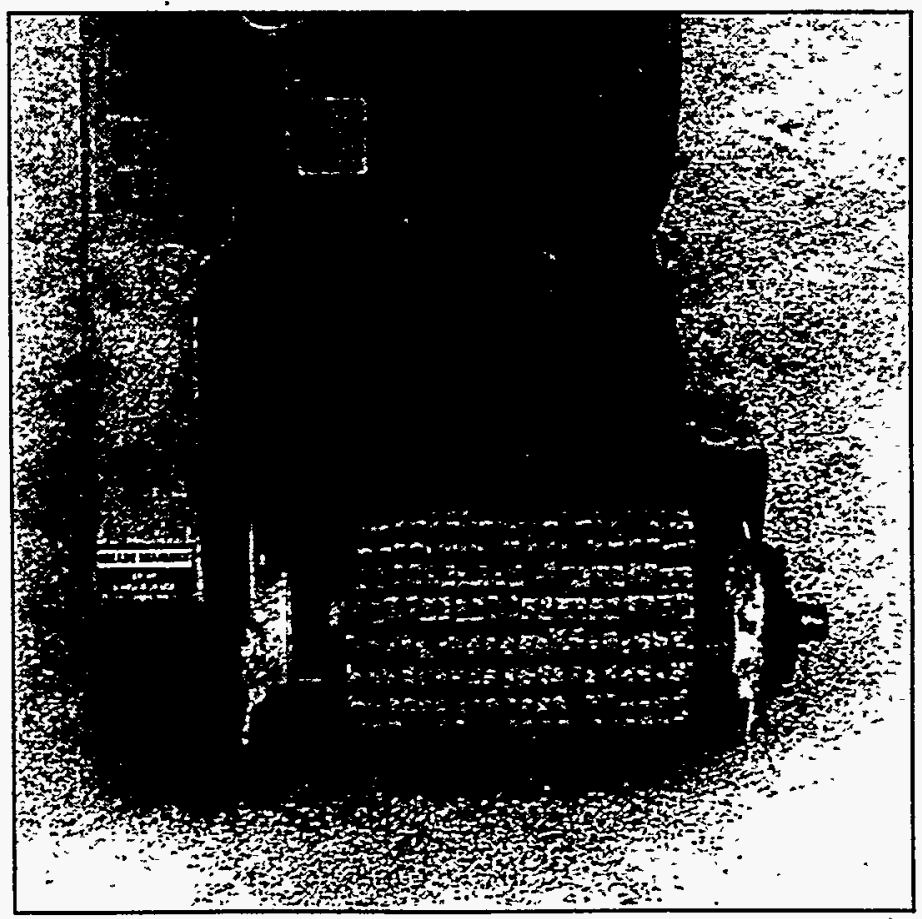

Figure D-1. Milling technology. 


\section{D.1.2 STEEL GRIT VACUUM BLASTING}

The LTC 1073 vacuum blaster tested can use a maximum of three blast heads. Compressed air carries the media to a nozzle, which accelerates the media and impinges the surface. The media scrape the coating, rust, and contamination from the surface. A vacuum system that surrounds the nozzle collects the media and surface removed. The vacuum system separates the usable media from the remaining debris, and the media are reused in the system. Many systems can operate a single nozzle or multiple nozzles, increasing production rates. Various grades and types of media are available to tailor the media to the surface conditions. Media type and the surface undergoing removal can dramatically modify the amount of secondary waste to be managed.

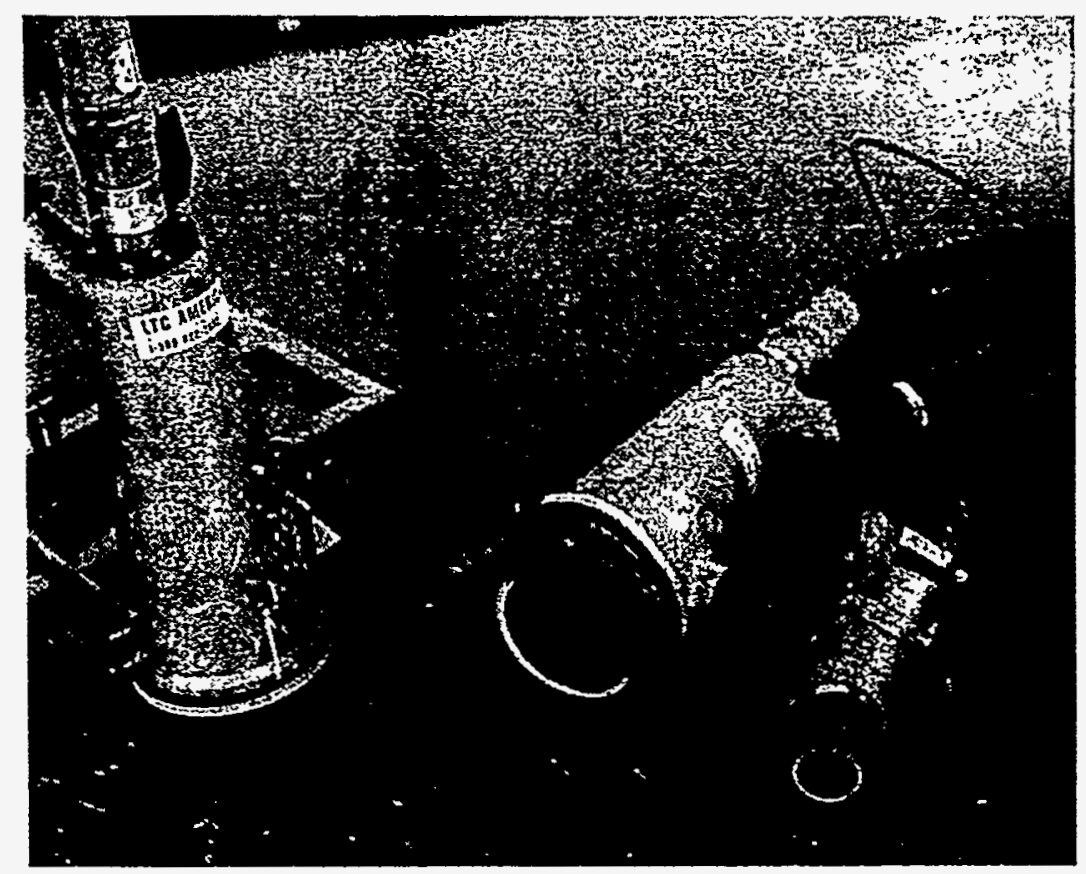

Figure D-2. Steel grit vacuum nozzles.

\section{D.2 DEVIATIONS}

The goal of this assessment was to identify technologies that can be applied directly to nuclear environment. In the case of the milling technology, this goal was not met during field testing.

The milling technology tested used a standard industrial vacuum cleaner not designed for a nuclear environment. The use of this vacuum system potentially skewed the data collected related to dust generation. The static pressure and flow requirements for the milling equipment are within the standard specification of many commercial nuclear vacuum systems;" thus, a standard High Efficiency Particulate Air (HEPA) filter nuclear vacuum can be used in conjunction with the milling equipment in a nuclear environment. 


\section{D.3 TECHNOLOGY RECOMMENDATIONS}

The intent of this section is to review the performance of the technologies tested and make recommendations as to ways to improve them based on the test results. It is important to note that while the recommended modifications may improve the system in one area of operation, they may adversely impact the technology's ability to excel in other areas.

In the case of all the technologies tested, no feedback was provided by the technology itself regarding the depth of removal achieved. In most cases, a 2 in. $\times 4$ in. piece of lumber was utilized during application to estimate the depth of removal. This method was inaccurate. It would be convenient to incorporate an immediate feedback system into the technology to inform the operator when the desired depth or residual contamination levels were reached.

\section{D.3.1 Milling}

The milling technology tested was a combination of an Equipment Development Company, Inc. (EDCO) piece of equipment and 3M Rotopeen abrasive flaps. The vacuum shroud on the EDCO equipment could not be adjusted to ensure a good seal of the interface with the concrete. Therefore, small pieces of debris were expelled from the vacuum shroud. The particles did not cause a projectile hazard, nor did they cause an airborne problem because of their significant size.

The shroud must be able to float to conform to various surface conditions, thus achieving a more consistent vacuum condition. The shroud worked more effectively when the technology was used in the direction in which the material moved toward the single vacuum connection. When the technology was operated in the opposite direction, the shroud provided minimal pickup. The shroud therefore should be redesigned for conditions in which the material is to be picked up in both directions of operation.

The milling technology tested was used with a non-nuclear commercial vacuum system. For use in a nuclear environment, a different vacuum system would be required. Of the three milling technologies tested, the closest any could get to the interface with the floor and the wall was three-quarters of an inch. An adaptation of the technology is therefore required to complete the last three-quarters of an inch.

\section{D.3.2 Steel Grit Vacuum Blasting}

The steel grit vacuum blaster employed two different size blast/vacuum heads to perform coating and surface removal. The smaller blast head was hand held, requiring the operator to bend over to operate the tool. This operator position resulted in operator fatigue within a few minutes. This position also produced an uneven surface finish. The operator was required to hold the nozzle against the surface and move it along the surface to achieve the required surface condition. The operator was unable to keep an even tempo, producing deeper perietration in some areas and very little penetration in others. In the areas of greater penetration where the aggregate was exposed, the grit became caught between the aggregate, and the vacuum system was unable to collect this grit. The design of the hand-held unit should be reviewed from an ergonomic perspective to reduce operator strain. 
The larger blast head was mounted on a cart, allowing the operator to stand upright while moving the blast head across the surface. This method reduced operator fatigue; however, the surface finish was uneven, resulting in deeper penetration in some areas and very little penetration in others. Spent grit remained in some of the deeper penetration areas where the aggregate was exposed. The operator had difficulty maintaining an even tempo to achieve a uniform finish. If the blast heads were mounted to a semi-automated transport platform from which the speed could be set, a much more even surface finish could be achieved. 